\title{
Editorial
}

\section{Mathematical Models for Dealing with Risk in Engineering}

\author{
Jurgita Antucheviciene, ${ }^{1}$ Gang Kou, ${ }^{2}$ Vida Maliene, ${ }^{3}$ and Egidijus Rytas Vaidogas ${ }^{4}$ \\ ${ }^{1}$ Department of Construction Technology and Management, Faculty of Civil Engineering, Vilnius Gediminas Technical University, \\ Sauletekio Aleja 11, LT-10223 Vilnius, Lithuania \\ ${ }^{2}$ School of Business Administration, Southwestern University of Finance and Economics, Chengdu 610072, China \\ ${ }^{3}$ Department of the Built Environment, Faculty of Engineering and Technology, Liverpool John Moores University, Byrom Street, \\ Liverpool L3 3AF, UK \\ ${ }^{4}$ Department of Labour Safety and Fire Protection, Faculty of Civil Engineering, Vilnius Gediminas Technical University, \\ Sauletekio Aleja 11, LT-10223 Vilnius, Lithuania
}

Correspondence should be addressed to Jurgita Antucheviciene; jurgita.antucheviciene@vgtu.lt

Received 15 August 2016; Accepted 15 August 2016

Copyright (C) 2016 Jurgita Antucheviciene et al. This is an open access article distributed under the Creative Commons Attribution License, which permits unrestricted use, distribution, and reproduction in any medium, provided the original work is properly cited.

This special issue aims to provide recent developments in dealing with risk in various fields of engineering. Risk is a ubiquitous phenomenon of modern society. The concept of risk is variously understood and used in engineering, economics, and earth and social sciences [1-3]. An existence of risk arises from a possibility of adverse physical and economic phenomena that can cause damage to business, property, communication networks, and natural environment. In engineering, risk is commonly divided into speculative risk of potential economic losses or gains and nonspeculative or pure risk related to damaging phenomena, such as failures and accidents of physical objects as well as disturbances in computer networks and damage to information systems [4]. Currently, the assessment and management of pure risk are a well-established area with prospects of development and a number of unresolved problems [5-7].

Articles published in this special issue prove that risk assessment and management have many facets. Dealing with risk in engineering will require the application of a variety of approaches, ranging from sophisticated probabilistic and statistical models to straightforward engineering judgement and common sense decisions [8]. The management of risk calls for its assessment, and this in turn requires the quantification of the uncertainty of adverse events and consequences posed by each event. This is a standard, general scheme of risk assessment [9]. However, an application of this scheme will often require the solving of "local" problems, say, prediction of wind speeds, estimation of individual failure probabilities, or analysis of failure propagation in safety-critical systems. Articles included in this special issue are devoted to a solution of such "local" problems. Most of them are from various fields of engineering and informatics; some are devoted to solving risk-related problems in management. A part of articles is devoted to problems of safety and security, whereas another part deals with the problem of reliability. Risk analysis and reliability assessment are closely related areas sharing many aims, principles, and methodological tools [10-12]. In that sense, articles of the present special issue dealing with reliability can be seen as a contribution to risk assessment and management.

In the article "A Novel Approach to Evaluate the TimeVariant System Reliability of Deteriorating Concrete Bridges" by $\mathrm{H}$. Tian et al., the authors propose a computational methodology developed for an assessment of time-variant reliability of concrete bridges. This methodology is based on the Monte Carlo simulation. It is used for evaluating system reliability of bridges subjected to environmental impacts. The lifetime structural performance of bridges is evaluated as well.

W. Liu et al. consider the problem of real-time railway traffic control when tracks break down at large railway stations. In the article "Real-Time Track Reallocation for Emergency Incidents at Large Railway Stations," the authors 
propose a mathematical programming model aimed at minimizing the total occupational time of station bottleneck sections to avoid train delays. Additionally, an algorithm based on simulated annealing and genetic algorithm is proposed to solve the optimization problem.

In the article "Reliability of Foundation Pile Based on Settlement and a Parameter Sensitivity Analysis," S. Zhang et al. propose a formula of foundation pile reliability index. This index is related to the probability of excessive pile settlement through the distribution function of the standard normal probability distribution. Based on the formula of reliability index, authors analyze the sensitivity of this index to various statistical parameters of the pile: coefficients of variation of calculated settlement, permissible limit of the settlement, measured settlement, safety coefficient, and the mean value of calculation model coefficient.

The article "Risk Analysis Based on AHP and Fuzzy Comprehensive Evaluation for Maglev Train Bogie" by C. Fan et al. considers the safety of a maglev train bogie system. A new method combining analytic hierarchy process and fuzzy evaluation is proposed to assess hazards inherent in the bogie system and posed by potential multiple failures of bogie subsystems. This combination is seen as an alternative to standard methods of risk assessment, namely, fault tree analysis and event tree analysis.

In the article "Time-Independent Reliability Analysis of Bridge System Based on Mixed Copula Models" Y. Liu and $\mathrm{X}$. Fan consider an estimation of the time-independent probability of bridge system failure. They propose mixed copula models for calculating joint failure probabilities of bridge systems. The copula models are used to express the nonlinear correlation between system failure modes. These models were developed by applying optimal copula functions with Bayesian selection criteria and the Monte Carlo method. Two-component and multiple-component systems with different configurations are considered in the article.

C.-C. Shih et al. studied fire safety in various laboratories in the article entitled "Investigation of Lab Fire Prevention Management System of Combining Root Cause Analysis and Analytic Hierarchy Process with Event Tree Analysis." Data on laboratory fire accidents are analyzed to identify the root causes of fires and draw out fire prevention strategies. The methods of root cause analysis, analytical hierarchy process, and event tree analysis are applied in combination to assess various strategies of fire protection in laboratories. The combination of these three methods is used to prioritize fire prevention measures.

In "Application of Probabilistic Method to Stability Analysis of Gravity Dam Foundation over Multiple Sliding Planes" by G. Wang and Z. Ma, the authors propose an approach to estimating the probability of instability of a concrete gravity dam foundation. The instability over multiple gliding places is considered. The problem of the instability probability calculation is solved by combining design point method with the method of divided differences. A performance function with nonnormal and correlated input variables is used for the probability estimation.

In the article "Quantification of Margins and Uncertainties Approach for Structure Analysis Based on Evidence
Theory" C. Xie and G. Li address the problem of structural reliability assessment carried out as uncertainty propagation. Aleatory and epistemic uncertainties related to a mechanical structure are modeled and propagated by a combined application of the methodology known as a quantification of margins and uncertainties (QMU) and the evidence theory. The authors propose a technique that allows the reduction of computational costs of the Monte Carlo simulation used for the uncertainty propagation.

L. Zhao et al. consider an assessment of safety-critical systems in the article entitled "Failure Propagation Modeling and Analysis via System Interfaces.” A novel approach to safety analysis based on system interface models is proposed. These models consider interactions between system components and the environment. The approach proposed by the authors is aimed at improving modeling of propagation of failures in the systems by applying interface automata and restricted reliability analysis.

In the article "The Method of Oilfield Development Risk Forecasting and Early Warning Using Revised Bayesian Network" Y. Zhong et al. propose a novel method for forecasting and early warning of risk related to oilfield development. This method uses neural networks to predict warning situation indices of oilfield development risk and risk warning degree. Bayesian network is applied to diagnose the reasons causing the risk. The risk considered in the article is of managerial nature.

In "Geometric Process-Based Maintenance and Optimization Strategy for the Energy Storage Batteries" by Y. Li et al., the authors analyze different main states in the life circle of energy storage batteries. In addition, they propose an optimized management strategy aimed at a minimization of longrun average costs of batteries. The strategy is used to define the time interval of detective and preventive maintenance and determine optimal corrective maintenance times related to health and reliability conditions.

In the article "Short-Term Wind Speed Forecasting Using the Data Processing Approach and the Support Vector Machine Model Optimized by the Improved Cuckoo Search Parameter Estimation Algorithm" by C. Wang et al., the authors study the problem of wind speed forecasting by means of a novel combination of data processing models. The combination is called the forecasting portfolio. It consists of empirical mode decomposition model and support vector machine model improved by a cuckoo search parameter estimation algorithm. The original data used for this forecasting are wind speed series recorded by wind turbines. The proposed forecasting portfolio is compared to alternative forecasting models by means of a case study.

In the article "A Grey Theory Based Approach to Big Data Risk Management Using FMEA” M. M. Silva et al. propose an approach to big data risk management based on failure mode and effect analysis (FMEA) and grey theory. The securityrelated risk posed by potential hacker attacks is considered. FMEA is used to determine and evaluate potential failure modes associated with big data dimensions in terms of data vulnerability. The grey analysis is applied to FMEA with the aim of allocating the relative importance of risk factors. 
The risk factors and their relative weights are expressed in linguistic terms that evaluate data failure modes.

In "Vehicle Coordinated Strategy for Vehicle Routing Problem with Fuzzy Demands" by C. Liu et al., the problem of routing of cargo vehicles is solved. The demands of individual nodes in routes are considered to be uncertain (fuzzy). A fuzzy reasoning constrained program model is formulated for the vehicle routing problem with fuzzy demands and a hybrid ant colony algorithm is proposed to minimize the total travel distance, unloading times, and amount of waste caused by a service failure due to fuzzy demands.

In summary, the present special issue does not seek to systematize the very diverse field of risk assessment and management in engineering. This special issue rather demonstrates how many-sided dealing with risk can be.

Despite the certain randomness inherent in the submission of manuscripts for publication, we believe that this special issue could be interesting to all those who have to deal with risk in the vast field of engineering.

\section{Acknowledgments}

We would like to thank the authors of articles published in the issue for their contribution. We are grateful to all anonymous reviewers for their valuable work.

\author{
Jurgita Antucheviciene \\ Gang Kou \\ Vida Maliene \\ Egidijus Rytas Vaidogas
}

[11] M. Rousand, Reliability of Safety-Critical Systems: Theory and Applications, John Wiley \& Sons, Hoboken, NJ, USA, 2014.

[12] D. J. Smith and K. G. L. Simpson, Safety-Critical Systems Handbook, John Wiley \& Sons, Hoboken, NJ, USA, 2011.

\section{References}

[1] J.-M. Flaus, Risk Analysis. Socio-Technical and Industrial Systems, John Wiley \& Sons, Hoboken, NJ, USA, 2013.

[2] J. Ofungwu, Statistical Applications for Environmental Analysis and Risk Assessment, John Wiley \& Sons, Hoboken, NJ, USA, 2014.

[3] L. Theodore and R. R. Dupont, Environmental Health and Hazard Risk Assessment: Principles and Calculations, CRC Press, Boca Raton, Fla, USA, 2012.

[4] E. R. Vaidogas, The Business of Safety: Managing Occupational and Industrial Risks, Technika, Vilnius, Lithuania, 2010.

[5] T. Aven, "Risk assessment and risk management: review of recent advances on their foundation," European Journal of Operational Research, vol. 253, no. 1, pp. 1-13, 2016.

[6] C. K. Pease and R. P. Gentry, "Systematic review in chemical risk assessment-a chemical industry perspective," Environment International, vol. 92-93, pp. 574-577, 2016.

[7] T. Aven, "Implications of black swans to the foundations and practice of risk assessment and management," Reliability Engineering \& System Safety, vol. 134, pp. 83-91, 2015.

[8] N. Singpurwalla, Reliability and Risk: A Bayesian Perspective, John Wiley \& Sons, Chichester, UK, 2006.

[9] L. T. Ostrom and C. A. Wilhelmsen, Risk Assessment: Tools, Techniques and Their Applications, John Wiley \& Sons, Hoboken, NJ, USA, 2012.

[10] M. Rausand, Risk Assessment: Theory, Methods, and Applications, John Wiley \& Sons, Hoboken, NJ, USA, 2011. 


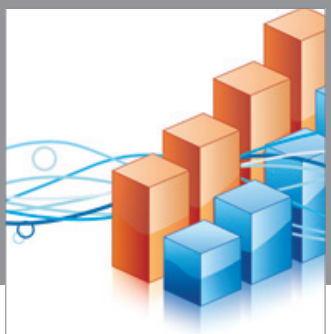

Advances in

Operations Research

vatem alat4

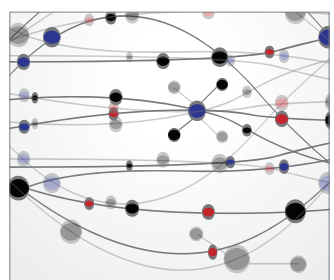

\section{The Scientific} World Journal
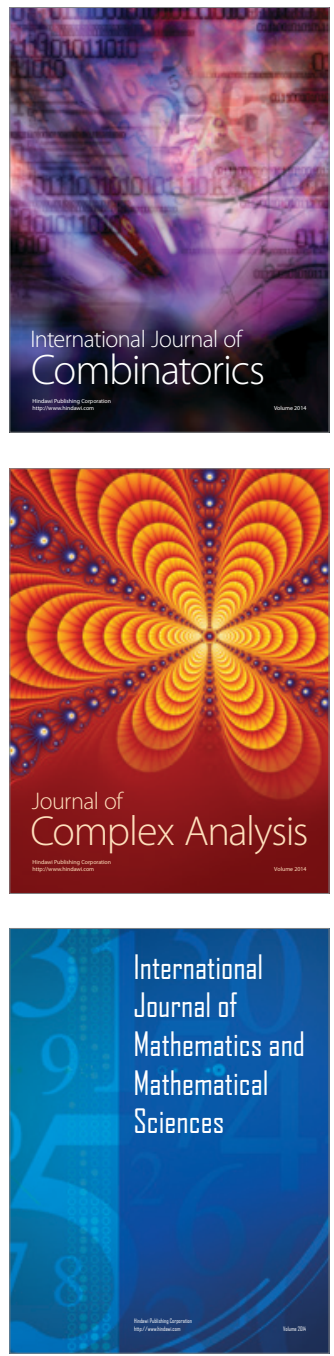
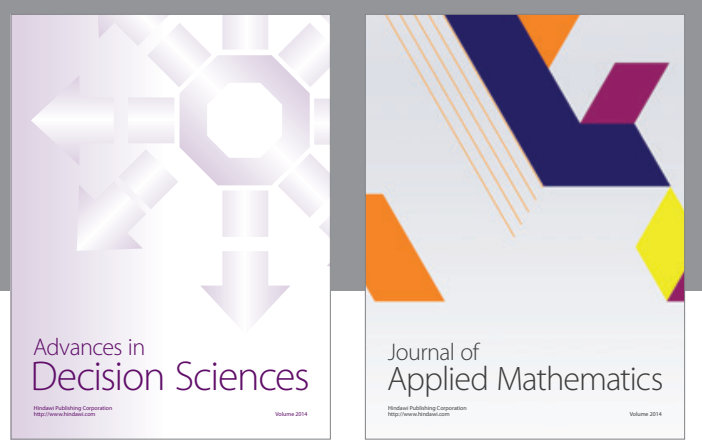

Algebra

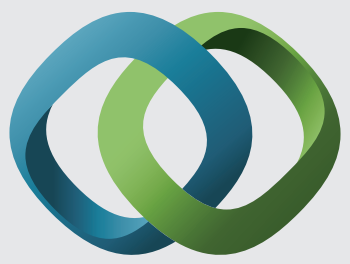

\section{Hindawi}

Submit your manuscripts at

http://www.hindawi.com
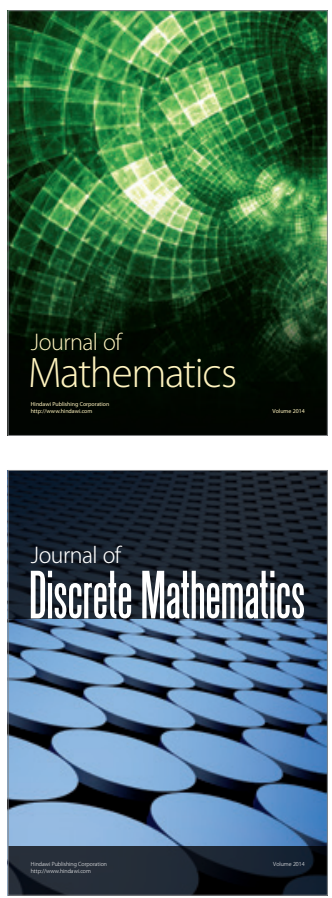

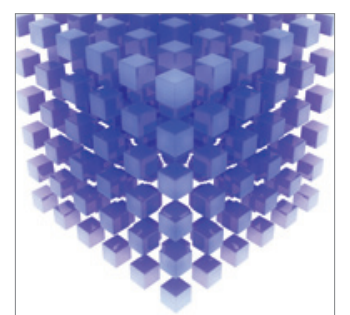

Mathematical Problems in Engineering
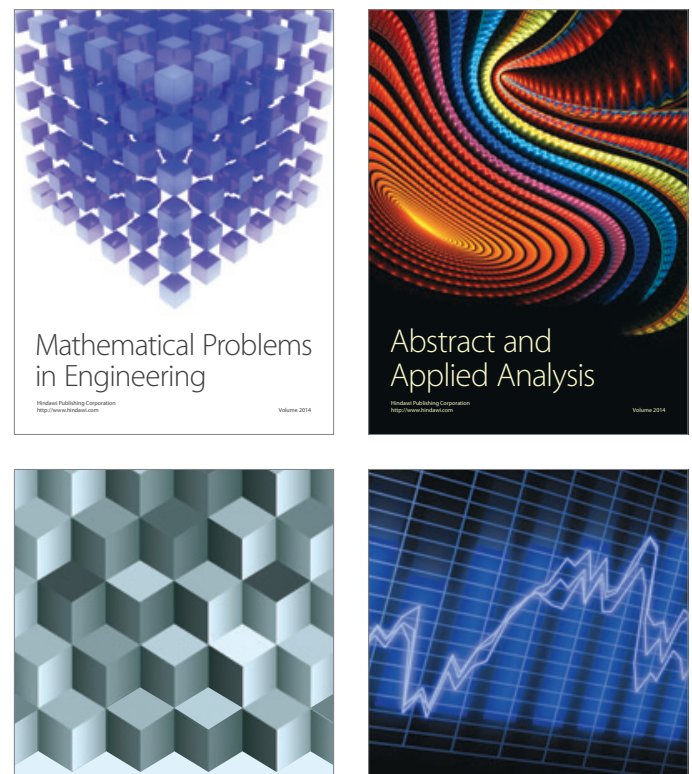

Journal of

Function Spaces



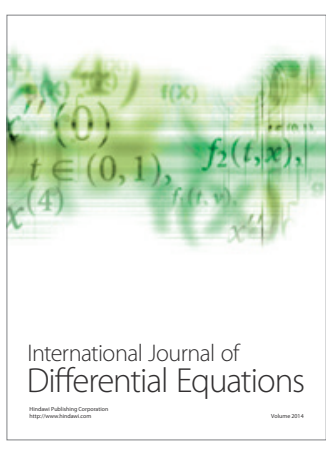
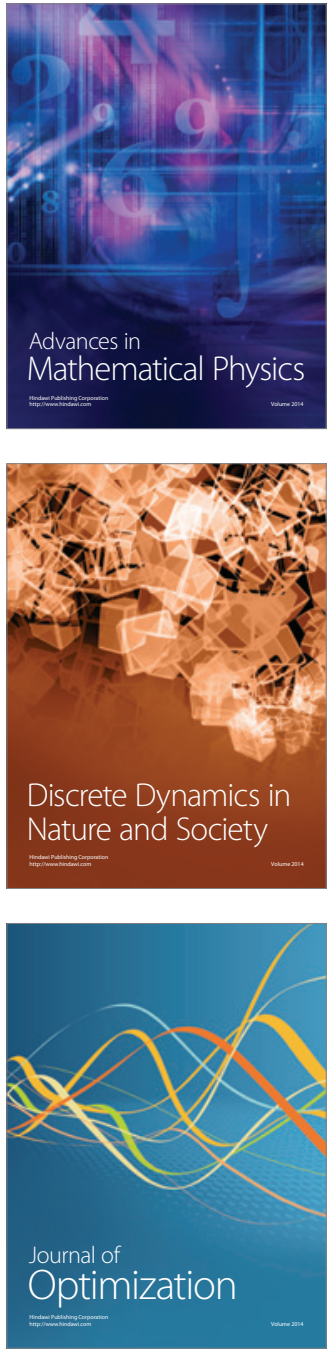